\title{
Monseñor Romero: diálogo y conflicto ${ }^{1}$
}

\author{
Héctor Grenni²
}

Monseñor Romero vivió en una época muy convulsionada, donde los conflictos se exacerbaron y buscaron la violencia como solución a las diferencias. La constante búsqueda del diálogo como forma de afrontar estos conflictos convirtió a Romero en un interlocutor frecuente de los sucesos de su tiempo. En este escrito se presenta la forma como Romero afrontó estos conflictos en los que el contexto que le tocó vivir lo envolvió.

Archbishop Romero lived immersed in a time of social upheaval, where the conflicts exacerbated and resorted to violence to resolve differences. The constant search for the dialogue to resolve the conflicts made Archbishop Romero a frequent interlocutor during the events of his time. This article presents how Archbishop Romero faced these conflicts and how he became involved in the context he had to go through.

\section{Presentación}

Monseñor Oscar Arnulfo Romero vivió en una época muy convulsionada, donde la efervescencia social se manifestó muchas veces bajo formas de violencia provocando una gran convulsión interna y un serio cuestionamiento del sistema social. Esto provocó, a su vez, un replanteamiento de las relaciones sociales, de las formas de producción y de distribución de la riqueza y del usufructo de los beneficios del sistema. ${ }^{3}$

A mediados de la segunda mitad del siglo XX, El Salvador presentaba una alta densidad de población $(250 \mathrm{hab} / \mathrm{km} 2)$, en una porción pequeña de territorio (20.000 km2), y graves situaciones de analfabetismo $(30 \%)^{4}$, injusticias (la riqueza concentrada en pocas personas ${ }^{5}$ ), y pobreza generalizada ${ }^{6}$.

1. Ponencia realizada en el III Congreso de la Red Universitaria para el estudio de la Fraternidad (RUEF), en Tucumán, Argentina, en agosto de 2010.

2. Director de la Biblioteca de la Universidad Don Bosco, y profesor de Doctrina Social de la Iglesia

3. Menjívar Ochoa, Rafael, Tiempos de Locura: El Salvador 1979-1981, FLACSO, Programa El Salvador, San Salvador, 2007, pág. 29.

4. Cfr. David Browning, El Salvador, la tierra y el hombre, Edición de la División de Publicaciones del Ministerio de Cultura y Comunicaciones, $3^{\circ}$ edición, San Salvador, 1987.

5. Sobre la concentración de la riqueza en El Salvador, ver Rodolfo Paniagua, El bloque empresarial hegemónico salvadoreño, Estudios Centroamericanos (ECA), Universidad Centroamericana José Simeón Cañas (UCA), número 645-646, San Salvador, 2002. También Colindres, Eduardo, Fundamentos económicos de la burguesía salvadoreña, Universidad Centroamericana José Siméon Cañas (UCA), San Salvador, 1977.

6. González, Luis Armando, Estado sociedad y economía en El Salvador (1880-1999), en Cardenal, Rodolfo y González, Luis Armando (compiladores), El Salvador: la transición y sus problemas, UCA Editores, San Salvador, 2007, pág. 35-41. 
Las relaciones entre las personas, y las relaciones entre las personas y la sociedad, en el marco de las realidades enunciadas, y en un contexto general de hacinamiento, difícilmente podían escapar a manifestaciones de violencia. De esta manera, el uso de los espacios comunes, como las plazas y las calles, se convirtieron en un lugar del cual puede apropiarse 'el que llega primero' y en una fuente permanente de conflictos.

Oscar Arnulfo Romero provenía de una familia campesina y católica. Fue sacerdote y obispo en una estructura eclesial sumamente comprometida con los sectores que detentaban el poder económico y político. ${ }^{7}$ Paradójicamente, su antecesor en el gobierno de la arquidiócesis, Monseñor Luis Chávez y González, dejó un clero y sectores laicales que comenzaban a formarse en los documentos del Concilio Vaticano Il y de Medellín y a cuestionar profundamente la postura de la Iglesia ante la situación de injusticia generalizada que hacía de contexto. ${ }^{8}$

La realidad que hizo de contexto a su breve trabajo en el arzobispado de San Salvador tuvo varios componentes: la conservadora estructura eclesial; el también conservador entorno social que le rodeaba; un clero y un laicado comprometidos con las exigencias de justicia, y un contexto general de país sumido en la pobreza y en el analfabetismo, y atado por la injusticia. Todas estas realidades interpelaron fuertemente a Romero, y lo obligaron a hacer que su discurso fuera cada vez más cercano a la realidad de su país. El diálogo entre esta persona -Monseñor Romero- y la realidad que lo interpelaba -El Salvador en la segunda mitad del siglo XX- dio lugar a un discurso con muchas facetas, interpretaciones y conflictos. ${ }^{9}$

La realidad que interpeló a Romero fue una realidad violenta: la segunda mitad de la década de 1970 en El Salvador vio el recrudecimiento de condiciones de vida cada vez más paupérrimas para la mayoría de habitantes; y vio surgir, quizá como reacción a este estado de cosas, movimientos de oposición al sistema y a los gobiernos de turno cada vez más radicalizados, hasta desembocar en la clandestinidad y la lucha armada. Son los años del surgimiento de movimientos guerrilleros que buscaban tomar el poder político por la violencia, para instaurar una sociedad sin marginaciones ni violencias. Aello respondió el poder constituido con una sangrienta represión, que tuvo por protagonistas a las fuerzas armadas por el estado: policiales, para-policiales y Fuerzas Armadas. Las violaciones a los derechos humanos se convirtieron en una cuestión cotidiana. ${ }^{10}$

7. Delgado, Jesús, ‘Oscar Romero. Biografía’, UCA Editores, San Salvador, 1990, pág. 22.

8. Simán, José Jorge, Monseñor Óscar Arnulfo Romero y Galdámez. Un testimonio, sin datos editoriales, San Salvador, 2007, pág. 4.

9. Morozzo Della Rocca, Roberto, Oscar Romero: Un vescovo centroamericano tra guerra fredda e rivoluzione” (Óscar Romero, un obispo centroamericano entre guerra fría y revolución), con prólogo de Roger Etchegaray, Mondadori Ed., Milán, 2002.

10. Martínez, Ana Guadalupe, Las cárceles clandestinas, UCA Editores, San Salvador, 1992, 2 edición, pág. 22. 
Quienes hicieron de Romero una bandera, después de su asesinato, lo presentaron como 'un luchador por la justicia', 'la voz de los sin voz', 'la voz de los pobres', etc. Sin duda fue una persona cercana a los sectores marginados, y con frecuencia interpretó sus sentimientos. Su discurso fue haciéndose cada vez más crítico a partir de 1977, el año en que asumió su trabajo en San Salvador.

Monseñor Romero escribió y dijo mucho: sus homilías llegaron a durar más de una hora y eran escuchadas por mucha gente, ya que eran transmitidas por varias radios. Escribió cuatro cartas pastorales; con frecuencia ofreció entrevistas y discursos por la radio. Y, si bien a veces se 'salía del libreto', improvisando, su pensamiento quedaba registrado: sus allegados grababan cuanto decía, especialmente desde fines de 1977 hasta su muerte, el 24 de marzo de 1980.

Las fuentes directas que presentan el pensamiento de Romero son, fundamentalmente, dos: sus homilías y sus cuatro cartas pastorales; quizá habría que agregar sus declaraciones en entrevistas y discursos en ocasión de la aceptación de los dos doctorados honoris causa que recibió. De las primeras tenemos registro cuidadoso, pues sus escritos preparatorios de esas homilías fueron cotejados con las grabaciones que se tenían de ellas. La publicación de la transcripción de estas homilías ya lleva varias ediciones. De sus Cartas Pastorales hay numerosas ediciones. De sus declaraciones y discursos, hay, también, numerosas publicaciones. A todo ello habría que agregar su Diario, escrito desde marzo de 1977 hasta su muerte. De todas ellas hay registros en sitios de Internet. ${ }^{11}$

En su pensamiento siempre se ha resaltado el tema de la defensa de la vida de todas las personas, en un tono fuertemente opositor al gobierno de su país, denunciando abiertamente las violaciones a los derechos humanos. Es conocido, además, por el carácter marcadamente pastoral de su pensamiento.

Hay, además, numerosos testimonios orales acerca de los dichos de Romero y sus reacciones ante hechos cotidianos, especialmente de personas que convivieron con él. Sin embargo, creemos que, con frecuencia, estos testimonios están empañados por el afecto o por las secuelas de luchas ideológicas posteriores.

Mucho se ha escrito acerca de Monseñor Romero. De hecho, es conocido en muchas partes del mundo, en ámbitos cristianos y no cristianos. Siendo él cristiano católico, su personalidad ha trascendido este ámbito. Actualmente es conocido también en ambientes cristianos no católicos, como el ámbito de la Iglesia Anglicana: en la catedral de Canterbury, la más importante de esta comunidad eclesial, tiene un lugar junto a los 'doce mártires del siglo XX'; el pensamiento de Romero es citado con frecuencia en este ámbito. Asimismo, en

11. Sugerimos http://servicioskoinonia.org, http://www.cervantesvirtual.com/bib_autor/romero/ y el foro sanromero@gruposyahoo.com 
la Iglesia Ortodoxa Rusa y en todo el ámbito del ortodoxismo se reproducen sus dichos y su pensamiento.

Incluso fuera de los ambientes cristianos, su pensamiento aparece con frecuencia citado en opúsculos, grafitis, camisetas, tarjetas, agendas, etc. Es conocido, especialmente, en ambientes religiosos cristianos vinculados con la teología de la liberación, con estudios acerca del pensamiento social cristiano y opciones pastorales que hacen hincapié en la opción por los sectores menos privilegiados.

Monseñor Oscar A. Romero no era un historiador ni un sociólogo, y no pretendía hacer profundas reflexiones acerca de la Historia. Pero su pensamiento teológico está profundamente enraizado en la realidad social, política y económica que le hace de contexto. Romero no escribió ni teorizó sobre la Historia. Su campo de pensamiento fue la Teología. El diálogo entre Romero y la realidad histórica fue realizado desde la Teología, una Teología basada en la realidad histórica que lo acompañó, especialmente durante los tres años de su trabajo como arzobispo de San Salvador.

\section{Breve biografía de Monseñor Romero}

Monseñor Oscar Arnulfo Romero Galdámez nació el 15 de agosto de 1917 en un pequeño poblado llamado Ciudad Barrios, del departamento de San Miguel, El Salvador, y murió asesinado el 24 de marzo de 1980 en la capital del país, San Salvador. ${ }^{12}$ Fue arzobispo de San Salvador entre febrero de 1977 y marzo de 1980. Precisamente, en el momento de su asesinato oficiaba una misa en el Hospital para enfermos de cáncer de la Divina Providencia. Bastó una sola bala desde el fondo de la iglesia, tirada por un asesino profesional, con una buena arma. ${ }^{13}$

Fue obispo auxiliar de San Salvador desde 1979 hasta 1974, época en que dirigió el semanario católico de la arquidiócesis, Orientación. En el último editorial escrito por Romero en ese semanario, al dejar su dirección para trasladarse a la diócesis de Santiago de María, el 15.10.1974, decía:

Lo que sí lamentamos, más con comprensiva tolerancia y paciencia que con actitud de resentimiento polémico, ha sido la conducta manifiestamente materialista, violenta y descontrolada de quienes han querido valerse de la religión para destruir las bases mismas espirituales

\footnotetext{
12. Hay numerosas biografías de Romero. Muchas de ellas están en opúsculos, impresos artesanales, la mayoría de ellos cargados de emotividad. Hay otras, frecuentemente parciales, especialmente editadas por la Universidad Centroamericana José Simeón Cañas (UCA). Con todo, recomendamos la última biografía escrita hasta ahora acerca de Romero: la de Roberto Morozzo della Rocca, “Oscar Romero: Un vescovo centroamericano, ya citada. 13. Saravia, Álvaro, en El Faro (periódico digital), 22 de marzo de 2010, 'Así matamos a Monseñor Romero', en http://www.elfaro.net/
} 
de la religión. En nombre de la fe han querido luchar contra la fe los que han perdido la fe. $Y$ esto es muy triste, verdaderamente triste. Por nuestra parte, hemos querido apegarnos a lo seguro, adherirnos con temor y temblor a la roca de Pedro, ampararnos a la sombra del magisterio eclesiástico, poner el oído junto a los labios del Papa, en vez de irnos por ahí como acróbatas audaces y temerarios por las especulaciones de pensadores atrevidos y de movimientos sociales de dudosa inspiración.... ${ }^{14}$

Fue Obispo de Santiago de María, en el oriente del país, desde 1974 hasta 1977. Hasta llegar a San Salvador fue considerado un obispo espiritualista, devoto, apostólico y hasta puritano, más inclinado a la componenda con los poderosos que a la solidaridad con los marginados. Incluso muchos de sus contemporáneos hablan de una 'etapa conservadora' en la vida de Romero.

Quizá por ello fue que el gobierno del presidente de El Salvador en 1976, General Arturo Molina, y los grupos de presión económica, ante la renuncia del entonces arzobispo de San Salvador, Monseñor Chávez y González, promovieron su nombramiento para el cargo. Prefirieron a Romero por sobre Monseñor Arturo Rivera Damas, obispo auxiliar de San Salvador y candidato 'natural' por su antigüedad, por ser éste considerado 'democristiano-comunista'.

Las circunstancias políticas y eclesiales que hicieron de contexto a esta elección eran sumamente tensas. El país estaba viviendo un frustrado intento de modificación de las estructuras existentes por medio de una reforma agraria que quedó trunca apenas comenzada. La reforma agraria, una iniciativa del gobierno del General Molina, sancionada por la 'Ley del ISTA' (Instituto Salvadoreño de Tecnología Agraria) en 1976, que buscaba frenar el creciente descontento y la efervescencia campesina, fue rápidamente abortada por la oposición de los terratenientes cafetaleros. El desencanto que ello provocó, unido a la secular situación de miseria y escasez de horizontes y esperanzas de las grandes mayorías del país, especialmente en el sector campesino, había llevado al país a una situación de explosión social. ${ }^{15}$

El gobierno intentó controlar esta efervescencia popular por medio de una ola represiva, encaminada a ahogar en sangre las expectativas y a calmar a quienes habían visto amenazados sus privilegios ancestrales. Esta represión continuó durante los años de gobierno democristiano del Partido Demócrata Cristiano. Éste llevó a la presidencia del país al Ing. Napoleón Duarte, en la década de los años ' 80 , y también propuso una reforma agraria, también ésta abortada por la oposición de los terratenientes. Esta situación fue comentada varias veces por Romero, señalando la reforma como una acción de beneficio para el pueblo ("la

14. Delgado, Jesús, op.cit., pág. 33.

15. Martínez, Ana Guadalupe, op.cit., pág. 92. 
reforma agraria es una necesidad teológica'), pero que, al estar acompañada de fuertes acciones de represión, terminaba por cuestionar el mismo intento de reforma. ${ }^{16}$

Los hechos que se sucedieron apenas Romero llegó a San Salvador precipitaron su definición en favor de los marginados del sistema, causando estupor en el gobierno y en los grupos de poder en el país, y en la curia vaticana, que habían llevado al arzobispado 'a un obispo piadoso, más dado a las componendas que a la crítica del sistema'. Este estupor, probablemente, fue sentido también en la representación del gobierno de Estados Unidos en El Salvador.

Poco a poco, Romero fue convirtiéndose en 'Monseñor' para todos. MartínBaró presenta este cambio como 'una transformación, un cambio radical, una verdadera conversión'17.

Soplaban los vientos del Concilio Vaticano Il y Medellín: la Conferencia Episcopal Latinoamericana (CELAM) se había reunido en 1968 en Medellín, Colombia, y había emitido un documento de análisis de la realidad sumamente crítico. Este documento contribuyó a formar el pensamiento de Romero, al punto de citarlo frecuentemente. ${ }^{18}$

La mayoría de los biógrafos de Romero coinciden que comenzó aquí una etapa de cuestionamiento interno: en un primer momento, se resistió con honestidad a los cambios que proponía el documento de Medellín y hubo momentos en que acusó de marxistas a los ideólogos de dichos documentos. En esos tiempos tomó represalias verbales en contra de los jesuitas del Colegio Externado San José, dirigido por los jesuitas, a los cuales más adelante defendería públicamente con apasionamiento ${ }^{19}$. En esa época conoció al sacerdote Rutilio Grande y a Monseñor Rivera Damas. Con ambos llegó a entablar una amistad profunda. Rivera Damas y Romero fueron obispos auxiliares de Monseñor Chávez y González en la arquidiócesis de San Salvador hasta que Romero fue nombrado obispo de Santiago de María.

Así, ante la conformidad de algunos y la oposición de otros, Romero fue nombrado arzobispo de San Salvador. La ceremonia de asunción del cargo se realizó en el Seminario San José de la Montaña, en San Salvador, el 22 de febrero de 1977 y se caracterizó por su sencillez y por no contar con la presencia de

16. Naciones Unidas, Comisión de la Verdad, Informe. De la locura a la esperanza. La guerra de 12 años en El Salvador, 1992-93, San Salvador, 1995.

17. Sobrino-Martín Baró-Cardenal, La voz de los sin voz, UCA Ed., 1999, pág. 14.

18. Acerca de la influencia del documento de Medellín en el pensamiento de Romero, véase la Tercera Carta Pastoral de Monseñor Romero y Primera de Monseñor Arturo Rivera Damas, titulada "La Iglesia y las organizaciones políticas populares”, de agosto de 1977. Hay una buena edición en Cartas Pastorales y Discursos de Monseñor Oscar A. Romero, publicado por el Centro Monseñor Romero de la Universidad Centroamericana José Simeón Cañas (UCA), en San Salvador, en 2007.

19. Ver, por ejemplo, su homilía en la misa de 26.06.77. 
autoridades civiles ni militares: era la primera vez en la historia del país que un arzobispo asumía su cargo en estas circunstancias. Esto no dejó de llamar la atención en todos los niveles, especialmente en los sectores de decisión política y económica. ${ }^{20}$

A los pocos días de asumir su trabajo en San Salvador, el 12 de marzo de 1977, Romero recibió la noticia del asesinato de su amigo el sacerdote Rutilio Grande junto a dos campesinos. ${ }^{21}$ Grande era párroco de la localidad de Aguilares, cerca de San Salvador, donde defendió los derechos de los campesinos y había contribuido decididamente en el proceso de concientización de los campesinos de la zona; prueba de ello son las numerosas asociaciones de campesinos que se formaron en esos años. Ello le granjeó la enemistad de los terratenientes.

Ante la muerte de Grande, Monseñor Romero escribió una carta al entonces presidente Molina, en la cual le manifestaba que no asistiría a ningún acto oficial mientras no se hiciera una investigación profunda y se esclareciera el crimen, cosa que nunca se hizo:

...Sumamente preocupado por el asesinato perpetrado en el Padre Rutilio Grande y dos campesinos de su parroquia de Aguilares que le acompañaban, me dirijo a usted para manifestarle que surgen en torno a este hechos unas serie de comentarios, muchos de ellos desfavorables a su gobierno. Como aún no he recibido el informe oficial que usted me prometió telefónicamente el sábado por la noche, juzgo de suma urgencia que usted ordene una investigación exhaustiva de los hechos, dado que el supremo gobierno tiene en sus manos los instrumentos adecuados para investigar y ejecutar la justicia en el país... La Iglesia está dispuesta a no participar en ningún acto oficial del gobierno, mientras éste no ponga todo su empeño en hacer brillar la justicia sobre este inaudito sacrilegio que ha consternado a toda la Iglesia y probado en todo el país una nueva ola de repudio a la violencia... ${ }^{22}$

El crimen nunca quedó aclarado, y de esta manera, en sus tres años de trabajo en San Salvador, Romero nunca asistió a ningún acto del gobierno. Así, se sucedieron tres cambios de presidente, y un cambio de Asamblea Legislativa y otros actos oficiales sin la presencia del arzobispo de San Salvador. ${ }^{23}$ Las personas cercanas al obispo comentan que, probablemente, desde ese momento tomó la opción de estar más cerca de los sectores marginados.

20. Editorial de El Diario de Hoy del 24.02.77.

21. Cardenal, Rodolfo, Historia de una Esperanza, vida de Rutilio Grande, UCA, San Salvador, 2002.

22. Fragmentos de la carta escrita por MR al Presidente Molina, el 14 de marzo de 1977. Citado por James R. Brockman en La Palabra queda. Vida de Mons. Oscar Romero, UCA Editores, San Salvador, 1985, pág. 98.

23. Véanse los comentarios en el periódico La Prensa Gráfica, del 2 de julio de 1977, al asumir el poder político el nuevo presidente, General Romero. 
Los acontecimientos se precipitaron desde entonces. En los tres años que duró su trabajo en la arquidiócesis de San Salvador, escribió cuatro Cartas Pastorales; asesinaron a siete sacerdotes, un canciller y otros funcionarios; la represión por parte del gobierno causó la muerte de numerosas personas; recibió dos Doctorados Honoris Causa; escribió varias cartas a los presidentes de turno reclamando por la ausencia de investigaciones o por la feroz represión; escribió una carta al presidente de Estados Unidos exigiendo el cese de la ayuda militar; dialogó con guerrilleros, sindicalistas, presidentes, ministros y funcionarios; hizo numerosas homilías que fueron escuchadas por muchísima personas en el país y en el extranjero...

\section{Romero: diálogo y conflicto}

Sin duda, Romero fue una persona muy influyente en esos tiempos. Con frecuencia era tomado como referencia en asuntos tanto eclesiales como nacionales. Así sucedió con la naciente guerrilla. Un contemporáneo suyo, Antonio Cardenal, cuenta en este testimonio recogido de militantes de la guerrilla:

-Vengan, que empieza la homilía!

Yo estaba clandestino, era jefe de milicias del Frente Paracentral. Todos los domingos, en todos los colectivos de las FPL en los que yo estuve, escuchábamos juntos las homilías de Monseñor Romero. Era parte de nuestra tarea de educación política. No es que fuera obligatorio oírla, pero nadie se la perdía.

Aún me acuerdo, todos pendientes de los que el 'viejito decía. Y a veces hasta lo aplaudíamos, escondidos entre las cuatro paredes de una casa de seguridad, cuidando de no hacer ruido. Cuando acababa tocaba comentar la homilía entre todos. Ah, los compas campesinos le tenían tremenda veneración a Monseñor. ${ }^{24}$

Lo mismo sucedió con algunos funcionarios de los gobiernos. Sirva como ejemplo la visita que hicieron a Romero varios miembros de la Junta de Gobierno que tomó el poder el 15 de octubre de 1977, que se llegaron hasta el Hospital de la Divina Providencia donde residía, para consultarle.

Fue corta esa primavera. El golpe, la juventud militar prometiendo cambios, las esperanzas... Qué va a ser... El poder seguía siendo de los viejos militares y de la oligarquía de toda la vida.

Llegaron un día de aquéllos el Coronal Majano y el Coronal García a visitar a Monseñor Romero en el hospitalito.

-Necesitamos que usted nos exprese con mayor claridad su apoyo- le

24. Citado por López Vigil, María, ‘Monseñor Romero, piezas para un retrato’, UCA Editores, San Salvador, $5^{\mathrm{a}}$ ed. 2001, pág. 325. 
dijo Majano.

- ¡A nosotros, pues!- remató García.

Monseñor se había cansado, y hasta quemado, expresando ese apoyo a los miembros civiles de la Junta y del gabinete. En ellos sí tenía una gran confianza.

-El gobierno atraviesa una crisis y una palabra suya nos puede ayudar mucho...

Después de un rato de estar escuchándolos a los dos militares, los ojos bajos, Romero los miró a la cara.

- Todo lo que ustedes me indican y me piden lo miro muy bien, pero hay algo en este gobierno que a mí no me parece.

-¿Y qué es, Monseñor?- le dijo ansioso Majano.

_Que se haya nombrado Ministro de Defensa desde el comienzo, y se mantenga después de dos meses en ese cargo, a un militar tan represivo como es el Coronel José Guillermo García.

-¡Óigame -le dijo el aludido- que yo soy el Coronel García!

-Ya lo sé, y precisamente por eso lo digo, porque a mí me gusta decir las cosas de frente.

Romero lo miró detenidamente, peroya no le dijo más. Tampoco hablaron los dos militares. Salieron del hospitalito con paso marcial. ${ }^{25}$

Quizá quienes mejor pueden definir a Romero son sus contemporáneos, los que trabajaron cerca de él. Veamos este recuerdo del sucesor de Romero en la arquidiócesis de San Salvador, Monseñor Arturo Rivera Damas:

Al final yo estaba convencido de que lo iban a matar.

Todos los obispos estábamos citados a una reunión en Ayagualo. Unos días antes de aquella reunión, Roberto D'Aubuisson había salido por televisión hablando barbaridades de Monseñor Romero. Y cuando aquel hombre abría la boca, al poco se abría una tumba. Por eso yo estaba convencido.

Vine a la reunión en San Salvador con esa preocupación pesándome en el alma. $Y$ hasta con temor. Tanto temor que ni siquiera quise montarme en el mismo vehículo de Monseñor Romero y decidí llegar por mi cuenta y en mi jeep.

En la reunión tocaba elegir presidente y vicepresidente de la Conferencia Episcopal. Estábamos cuatro de un lado y nosotros dos del otro. Monseñor Romero y yo estábamos convencidos de que si votábamos al presidente de entre ellos cuatro, ellos cuatro votarían al vicepresidente de entre nosotros dos.

-Parece lo más lógico- dijo él.

-Parece lo más justo- dije yo.

25. Testimonio de Armando Oliva, recogido por López Vigil, María, op.cit., pág. 334. 
Y así votamos. Pero nos falló el cálculo, porque los cuatro sacaron de entre ellos cuatro los dos cargos.

Monseñor Romero salió de Ayagualo muy defraudado. Mucho. Fue la última batalla que dimos juntos. Y la perdimos. ${ }^{26}$

Veamos ahora este recuerdo del sacerdote jesuita Jon Sobrino, a propósito de la toma y posterior retiro de las fuerzas del Ejército y de la Guardia Nacional de la iglesia ocupada en el pueblo de Aguilares.

Al terminar la misa Romero nos invitó a hacer una procesión con el Santísimo por las calles, como desagravio a la profanación que habían hecho los guardias.

Salimos de la iglesia cantando. Era un día de calor tremendo y Monseñor Romero iba empapado en sudor bajo la capa pluvial roja. Llevaba en alto la custodia. Delante de él, cientos de personas. Fuimos rodeando la plaza, cantando, rezando. La alcaldía frente a la iglesia estaba repleta de guardias que observaban. Cuando nos acercamos, varios de ellos se pusieron en mitad de la calle, apuntándonos con sus fusiles. Salieron más. Abrían las piernas, desafiantes, con sus grandes botas, y formaron una muralla para que no pasáramos. Los que iban a la cabeza se quedaron inmóviles, y luego los de más atrás. La procesión se detuvo. Frente por frente, nosotros y sus fusiles. Cuando ya nadie se movía, nos volteamos a mirar a Monseñor Romero, que venía de último. Alzó un tanto más la custodia y dijo en voz alta para que todos oyeran:

- iAdelante!

Entonces seguimos avanzando hacia los soldados poco a poco y ellos comenzaron a retroceder también poco a poco. Nosotros hacia ellos y ellos hacia atrás. Después hacia el cuartel. Terminaron por bajar los fusiles y nos dejaron pasar.

Desde aquel día, y como aquel día, en cualquier hecho importante que ocurrió en El Salvador, para seguirlo o para perseguirlo, siempre hubo que volver la vista hacia Monseñor Romero. ${ }^{27}$

Un nuevo intento de diálogo va a presentar Romero cuando, habiendo el Ejército y la Guardia Nacional ocupado el poblado de Aguilares, incluida la iglesia, vio impedido su ingreso al templo por la Guardia Nacional. El 23 de mayo de 1977 escribe al presidente en estos términos:

No me explico, señor presidente, cómo usted, por un lado se proclama católico de formación y convicción ante la faz de la nación y por otro permite estos atropellos incalificables de parte de los cuerpos de

26. Citado por López Vigil, María, op.cit., pág 365.

27. López Vigil, María, op.cit., pág. 160-1 
seguridad, en un país que llamamos civilizado y cristiano...No comprendo, señor presidente, los motivos que tuvieron las autoridades militares para no permitir al suscripto personarse en la Iglesia de Aguilares, para informarse de visu y garantizar la conservación del patrimonio eclesiástico del pueblo católico de Aguilares. ¿Es que la persona del arzobispo hace peligrar también la seguridad del estado? ${ }^{28}$

Este diálogo del cual Romero tomó la iniciativa se dirigió también a sectores humildes de la población, como los soldados. En una de sus homilías lee este mensaje que le mandaron algunos soldados que probablemente no encontraban otra forma de hacer públicas sus peticiones.

Tengo una carta muy expresiva de un grupo de soldados. ¡Bien reveladora! Voy a leer la parte que puede interesarnos más. 'Nosotros, un grupo de soldados, le pedimos que si nos puede hacer público los problemas que tenemos y nuestras exigencias que planteamos a nuestros señores oficiales y jefes y junta de gobierno y con su ayuda estaremos de antemano agradecidos. Lo que nosotros queremos es lograr la mejoría de las tropas y de la FAES: 1) mejoría del rancho, 2) que se evite el uso del garrote y el ultraje hacia la tropa, 3) que se mejore el vestuario de la tropa, 4) que se nos aumente el salario, pues lo que recibimos en definitiva es 200 o 300 colones mensuales, que si se toman en cuenta todos los descuentos que nos hacen, queda en nada, 5) que no se nos envíe a reprimir al pueblo'.

En este punto fue interrumpido por aplausos. Y continúa:

Queridos soldados, en este aplauso del pueblo pueden encontrar la mano tendida a esas angustias de ustedes. ${ }^{29}$

Romero vivió en tiempos de conflictos, decíamos arriba. Conflictos que venían de la realidad social y civil que le hacía de contexto y de la propia Iglesia: el Diario de Romero comenta las divisiones profundas en el seno de la Conferencia Episcopal de El Salvador, que llegó incluso a la injuria y la mentira. ${ }^{30} \mathrm{La}$ búsqueda empecinada de diálogo por parte de Romero frente a una posibilidad de expresarse, que no tendrían en otros lugares. Este fragmento de una homilía del 16.10.1977 presenta un caso de éstos.

La Iglesia apoya plenamente las justas exigencias de los campesinos. Ya se acercan las temporadas de las cortas de café, de caña, de algodón;

28. López Vigil, María, op.cit., pág. 159.

29. Homilía en la misa del 20.01.80, citado por María López Vigil, op.cit., pág. 341-2.

30. En agosto de 1978, Romero y el obispo de Santiago de María, Monseñor Rivera Damas, publicaron la Tercera Carta Pastoral de Monseñor Romero y Primera de Monseñor Rivera Damas, titulada 'La Iglesia y las organizaciones políticas populares'. Tres semanas después, los otros cuatro obispos del país publicaron otra carta pastoral con conceptos muy distantes de los expresados en la Carta Pastoral de Romero y Rivera Damas. 
y hemos visto en los periódicos también el deseo de aquella gente que solamente en esos días de trabajo encuentra sus fuentes de ingresos. Quien vive de cerca estas tremendas realidades sabe que el sueldo del cortador de café o de caña o de algodón muchas veces ya tiene comprometido todo lo que ha ganado o lo que va a ganar, porque ha tenido que vivir fiando durante todo el año para comer. Yahora pues, que estos productos que nuestra tierra, bendecida por Dios, han alcanzado altos precios, es justo que participen también aquellos que colaboran en este enriquecimiento. Y esto es simplemente justicia cristiana. Que se comparta, que se sepa agradecer a Dios el don recibido, los precios elevados de las cosas....

Decíamos más arriba que Romero buscó insistentemente el diálogo con los hechos de la Historia. Los temas recurrentes en este diálogo, son la vida, la violencia y con ello la paz, la adhesión a las ideologías, y la aceptación de todas las personas como sujetos de diálogo, sin exclusiones. Romero fue un continuo buscador de interlocutores. Las personas y los hechos encontraron siempre en él alguien dispuesto y preparado para la recepción. Esto se hace evidente por la continua alusión a los hechos cotidianos en sus opiniones públicas. Sabemos, por testimonios de personas que convivieron con él, que también en el diálogo constante e informal de todos los días, estos hechos eran motivo de constante intercambio. Recomendamos la lectura del mensaje realizado en su visita a la radio YSAX, el 8 de abril de1977, desde donde pronuncia una larga disertación, tratando temas muy diversos, que no reproducimos aquí por ser demasiado largo.

El diálogo de Romero con la realidad estuvo muchas veces marcado por la realidad acuciante de temas que interpelaban fuertemente y con urgencia. El tema de la vida sale continuamente a relucir en sus expresiones; esta situación es comprensible, en tiempos en que la efervescencia social era fuerte, y la violencia institucional y social producía asesinatos cotidianos. Ante esta situación, los obispos del país emitieron un mensaje 'Ante la ola de violencia que enluta el país', que Romero comenta en la homilía de la misa del 22.05.77, haciendo alusión a un documento ${ }^{31}$ de la Conferencia Episcopal de El Salvador:

El mensaje termina haciendo un llamamiento apremiante, una invitación, principalmente a los que tienen en sus manos los poderes político y económico, para que unidos a todas las fuerzas vivas del país, busquemos un camino que haga efectiva la justicia social como única salvación para evitar que el país caiga en la violencia y en los totalitarismos de cualquier tipo. El aferrarse más y más a sus intereses,

31. Se refiere al documento "Mensaje al Pueblo Salvadoreña ante la ola de violencia que enluta el país", de marzo de 1977, de la Conferencia Episcopal de El Salvador. No se había desatado aún la profunda división que se desataría pocos meses después en el seno de la Conferencia Episcopal. 
olvidando el clamor de los desposeídos, es crearle el ambiente propicio a las violencias totalitarias ${ }^{32}$.

Romero no se queda en el anonimato de un mensaje grupal. Lo hace propio, y citarlo en un mensaje público -sus homilías en las misas habían tomado ese carácter-implica asumir personalmente sus conceptos.

Un tema candente en esos tiempos era la ideología a la cual adherir. Romero quiso dejar clara su posición y la de la Iglesia que representaba acerca de la adhesión a esas ideologías, probablemente, en un intento de dotar de honestidad a este diálogo, dejando en claro desde cuál lugar se está hablando. Como en este texto, a principios del que citábamos arriba:

...distinguir entre el mensaje de la Iglesia y el comunismo, y cómo la Iglesia, así como rechaza el comunismo, rechaza también el capitalismo. ... Y por eso la Iglesia no puede ser ni comunista, ni capitalista, porque los dos son materialismo.

Oigan la declaración: primero 'La Iglesia -por eso- condena al marxismo comunismo que por ideología y práctica revolucionaria niega a Dios y niega todo valor espiritual, calificándolo de alienante', el comunismo no admite esta reunión que estamos haciendo en la Iglesia, la llama alienante, 'opio del pueblo, dormidera, para que los hombres no protesten'. ... El comunismo explota las diferencias de clase en la sociedad para provocar la lucha, y usa al hombre como puro medio para lograr u n poder político conforme a su ideología'. Esta es un síntesis de lo que es el comunismo. Pero con la misma intensidad condena la Iglesia el sistema liberal capitalista, que aunque confiesa a Dios, sin embargo, en la práctica lo niega poniendo su fe en el lucro, como meta esencial del progreso humano; asume al hombre como puro instrumento para incrementar las riquezas dejándolo en la pobreza y fomentando de este modo las diferencias de clase en la sociedad; pisotea los derechos del hombre, su dignidad y hasta la vida misma para conservar el poder político, social y económico adquirido. ${ }^{33}$

Este otro fragmento nos dice, siempre en el mismo contexto, que no dudó en proponer y adelantar juicios. Los siguientes conceptos podrían tildarse de arriesgados o inoportunos:

Derecha significa cabalmente la injusticia social. $Y$ no es justo estar manteniendo nunca una línea de derecha. ¿lzquierda? Yo no las llamo fuerzas de izquierda, sino fuerzas del pueblo. Y su violencia puede ser

32. Arzobispado de San Salvador, Mons. Oscar A. Romero. Su pensamiento, Tomo I, Ed. Librería del arzobispado, San Salvador, 2000, homilía del 10.07.77, pág. 61.

33. Arzobispado de San Salvador, Mons. Oscar A. Romero. Su pensamiento, Tomo I, Ed. Librería del arzobispado, San Salvador, 2000, homilía del 22.05.77. 
el fruto de la cólera ante esa injusticia social. Lo que llaman izquierda es el pueblo. Es organización del pueblo y son los reclamos del pueblo... Los procesos de los pueblos son muy originales. No podemos decir que hay un cliché para pasar del capitalismo al socialismo. Si se le quiere llamar socialismo, pues será cuestión de nombre. Lo que buscamos es una justicia social, una sociedad más fraterna, un compartir los bienes. Eso es lo que se busca. ${ }^{34}$

La constante mirada hacia la realidad caracterizó siempre el trabajo de Romero. Desde, como decíamos arriba, ese lugar de observación privilegiado que fue el arzobispado de San Salvador, propuso constantemente el diálogo político, incluso a costa de cuestionamientos severos a institutos políticos en ese entonces en el gobierno. Repasemos brevemente este mensaje que data del 17 de febrero de 1980, al Partido Demócrata Cristiano, incorporado a la Junta Revolucionaria de Gobierno.

A la Democracia cristiana le pido que analice no sólo sus intenciones, que sin duda pueden ser muy buenas, sino los efectos reales que su presencia en el gobierno está ocasionando. Su presencia está encubriendo, sobre todo a nivel internacional, el carácter represivo del régimen actual. Es urgente que como fuerza política de nuestro pueblo vean desde dónde es más eficaz utilizar esa fuerza en favor de nuestros pobres. Si aislados e impotentes en un gobierno hegemonizado por militares represivos o como una fuerza más que se incorpora a un amplio proyecto del gobierno popular, cuya base de sustentación no son las actuales fuerzas armadas, cada vez más corrompidas, sino el consenso mayoritario de nuestro pueblo. ${ }^{35}$

Son numerosas sus expresiones en este sentido, y resultaría demasiado largo citarlas todas. Nos parece oportuno, sin embargo, citar este otro texto, de un mensaje ya citado más arriba, del 12 de mayo de 1977, en el funeral del sacerdote Alfonso Navarro:

La violencia la producen no sólo los que matan, sino los que impulsan a matar. Yo quisiera dirigir mis palabras desde aquí al Señor presidente de la República; si son sinceras sus frases que ayer me decía por teléfono, que se iba a preocupar de investigar este crimen, lo mismo que se preocuparía y se está preocupando, supongo, por la vida de su canciller. Porque tan sagrada es la vida del Ing. Borgonovo, como sagrada es la vida del sacerdote que hoy perece, como sagrada es la vida del Padre Grande, que hace dos meses pereció también acribillado, y a pesar de las promesas de investigación, todavía estamos lejos de saber la

34. Entrevista concedida al Diario de Caracas, 19 de marzo de 1980, citado por María López Vigil, 'op.cit., pág. 330.

35. Homilía en la misa del 17.02.80, citado por María López Vigil, op.cit., pág. 340. 
verdad. ${ }^{36}$

El trabajo de Romero en la arquidiócesis de San Salvador estuvo marcado por la violencia, la misma que marcó el país entero por esos años. En esta situación de violencia, los hechos cotidianos y las personas estaban frecuentemente marcados por ella. Por ejemplo, los asesinatos en la vía pública de la ciudad se sucedían a diario, y las amenazas, muchas veces cumplidas, se hacían públicas. Una de ellas, reiterada frecuentemente, era la amenaza contra los jesuitas de San Salvador. Ante estas amenazas publicadas por radio, comentadas en la homilía de la misa del 26.06.77, Romero busca dialogar, improvisa, a veces con errores de sintaxis:

Un esfuerzo, hermanos, por perdonar; un esfuerzo por amar. Comenzando por amar a Dios y no ofenderlo, dejar el pecado y amar al prójimo, aunque me haya ofendido. Esta es la fuerza que hará un mundo mejor, y que el Papa ha llamado la Civilización del Amor. Proclamémosla y hagamos lo posible por construirla: La civilización. ¡Pero si es que hoy El Salvador no está civilizado! ¡Es que publicarse o echarse por radio amenazas tan brutales, tan animales como esa que ha salido últimamente! ¡Eso es muy subdesarrollo de civilización! (sic) ¡No poder soportar la luz de la razón de unos escritos! Si la razón se combate con razones. ¿Porqué amenazar con armas, con muerte, al que escribe la razón, el mensaje de la Iglesia? ${ }^{37}$

Este intento de dialogar va dirigido hacia todos los sectores, e incluye a los poderes públicos. Pocos días después del texto citado, intenta iniciar un diálogo con el nuevo presidente, el general Romero, en estos términos:

$Y$ éste es el diálogo que la Iglesia ofrece. Si el nuevo mandatario nos pedía que le tuviéramos confianza y que lo iba a demostrar, he aquí la Iglesia a la espera de ese diálogo. La Iglesia nunca ha roto el diálogo con nadie. Otros son los que lo han roto; otros son los que la han maltratado. Le diríamos que hay muchas palabras que no salen de la boca, pero que deben salir de las obras, para demostrar la sinceridad en esta búsqueda de paz para nuestra patria. Por ejemplo, la Iglesia necesita que le devuelvan a sus sacerdotes que le han quitado. Muchas familias necesitan que le devuelvan a sus seres queridos que no saben dónde están. Se necesitan muchas obras para ganar la confianza, y de verdad buscar en todos, con sinceridad, la paz que necesita nuestra patria. ${ }^{38}$

36. Arzobispado de San Salvador, Mons. Oscar A. Romero. Su pensamiento, Tomo I, Ed. Librería del arzobispado, San Salvador, 2000, homilía del 12.05.77, en la misa de los funerales del P. Navarro Oviedo.

37. Arzobispado de San Salvador, Mons. Oscar A. Romero. Su pensamiento, Tomo II, Ed. Librería del arzobispado, San Salvador, 2000, homilía del 26.06.77.

38. Arzobispado de San Salvador, Mons. Oscar A. Romero. Su pensamiento, Tomo II, Ed. Librería del arzobispado, San Salvador, 2000, homilía del 03.07.77. 
Y pocos días después de esto, se ofrece nuevamente al diálogo:

Esta misa, transmitida por radio desde la Catedral y celebrada por aquel servidor del pueblo de Dios que tiene el encargo de ser el signo de la unidad en toda la arquidiócesis, siempre me parece que resulta como una reunión de familia. Yo quisiera que así nos sintiéramos en este momento de reflexión: una familia, que no tiene prisa, que un fin de semana llega al hogar para ver cómo andan las cosas de familia, para ayudar, para colaborar. Comprendo que al mismo tiempo que se reúne la familia, si esta familia es muy importante tiene muchos enemigos, que la observan para criticarla, o quién sabe, lo que más le pido al Señor, para convertirse. ${ }^{39}$

Este diálogo estuvo hecho, además, de mensajes, llamados por teléfono, escritos, preguntas y respuestas, enmarcado en los hechos de todos los días. En la misma misa que citábamos arriba, decía:

...quiero también agradecer y destacar un estudio precioso. Quero decirle a su querido autor: que me ha arrancado lágrimas, cuando he leído ese estudio acerca de la correspondencia que estoy recibiendo a montones, y que gracias al Padre Guevara, encargado de este asesoramiento de la noticia y del informe de la curia, se ha llevado a un estudio psicológico, profundo, pastoral, cómo trazuma en esos millares de cartas, la mayoría de campesinos; pero no exclusivamente, también gente de sociedad, que comprende y vive el problema, y no se encierra en un egoísmo que da frío, sino que trata de comprender. ${ }^{40}$

Con frecuencia se acusó a Romero de intentar romper el diálogo iniciado; especialmente, se lo acusó de romper el diálogo con los gobernantes de turno. No creemos que esta haya sido la intención de Romero, como él mismo lo expresa el 14 de agosto de 1977: "La Iglesia no está peleada con el gobierno". ${ }^{41}$

En esos días los periódicos publicaban con frecuencia artículos contemplando la posibilidad de que 'la Iglesia se distancie del gobierno', como se puede ver en El Diario de Hoy, en casi todos los días de los meses de julio y agosto, y ocasionalmente en La Prensa Gráfica de esos tiempos. Recomendamos leer los periódicos de esos tiempos, especialmente el del 3 de agosto de 1977. Quizá este mensaje es un intento de ir al encuentro de estas consideraciones. De cualquier manera, es un intento de diálogo. Con todo, todas estas situaciones le valieron la adhesión de muchos y el odio de otros. Hasta que un grupo de estos

39. Arzobispado de San Salvador, Mons. Oscar A. Romero. Su pensamiento, Tomo II, Ed. Librería del arzobispado, San Salvador, 2000, homilía del 24.07.77, en una misa transmitida por radio.

40. Ídem

41. Arzobispado de San Salvador, Mons. Oscar A. Romero. Su pensamiento, Tomo II, Ed. Librería del arzobispado, San Salvador, 2000, homilía del 14.08.77. 
últimos, después de haberlo amenazado públicamente varias veces, planeó su asesinato. ${ }^{42}$

La postura de los medios de comunicación masiva en El Salvador, en esos tiempos, sin duda, contribuyó grandemente a la incentivar la violencia. Ante esto, la insistencia de Romero en sus mensajes, en mirar la violencia desde la paz se convirtió en un argumento reiterado. Y esta postura, en esos tiempos de violencia, revela además de un gran coraje, una postura definida al respecto. Su respuesta a la violencia con que lo interpelaba la realidad nunca fue violenta. Transcribimos sólo algunos pasajes de sus dichos acerca de este tema.

La paz consistirá, entonces, en ver qué quiere Dios de esta sociedad, qué quiere Dios de mi vida, qué quiere Dios de la República. Y eso debían de estar viendo los gobernantes y todos los constructores, y los que pueden cambiar los destinos de la patria, con su dinero, con su capacidad política, con su técnica, no fiarse de sus caprichos. Como buenos constructores debían de estar extendiendo continuamente el plan arquitectónico de nuestra patria, y construir sobre estas líneas. Entonces hay paz. Lo demás, como dice el Concilio: paz no es la ausencia de guerra. Paz no es equilibrio de fuerzas que están en pleito. Paz, sobre todo, no es el signo de muerte bajo la represión cuando no se puede hablar, paz de los cementerios. La verdadera paz es aquella que se basa en la justicia, en la equidad, en el plan de Dios que nos ha creado a su imagen y semejanza, y nos ha dado a todos los hombres la capacidad de construir al bien común de la República. No es un pequeño grupo el que Dios ha escogido, sino a todos los salvadoreños. Todos tenemos derecho a participar en nuestro propio destino, en nuestro propio bien común. No cabe entonces ninguna exclusión. Es derecho humano. ${ }^{43}$

Para Romero, la ausencia de la paz viene de la injusticia, siguiendo al documento de Medellín ${ }^{44}$. Así lo expresa en esta homilía de 1977:

Yo quisiera, queridos hermanos, como fruto de esta reflexión en vísperas del día de la patria, recordarles lo que la Iglesia enseña: que las estructuras sociales, el pecado social en que vivimos, hay que

42. La Comisión de la Verdad, el organismo internacional nombrado por las Naciones Unidas para la investigación de las violaciones a los derechos humanos cometidos en el conflicto, surgida de los Acuerdos de Paz que pusieron fin al conflicto, determinó que un grupo de personas lideradas por el Mayor Roberto D'Aubuisson planearon y encargaron el asesinato de Romero. Probablemente, la homilía del 23 de marzo de 1980, donde Romero instó públicamente a los miembros de las policías y del Ejército a no obedecer una orden de matar porque va contra la ley de Dios, apresuró su ejecución. El audio de la homilía está disponible en Internet en el sitio de la Biblioteca Virtual Cervantes.

43. Arzobispado de San Salvador, Mons. Oscar A. Romero. Su pensamiento, Tomo II, Ed. Librería del arzobispado, San Salvador, 2000, homilía del 14.08.77.

44. CELAM, Documento de Medellín, 2 Paz, 14. Hay numerosas ediciones. Sugerimos la página oficial, http:// www.celam.org/principal/ 
cambiarlo. Todo esto tiene que cambiar, esto no puede seguir así. Todos los atropellos que mencioné al principio. Cambian de nombre las víctimas; pero la causa es la misma. Vivimos una situación de desigualdad, de injusticia, de pecado; y no es el remedio reprimir con la fuerza de las armas, para matar la voz que habla. Eso no remedia nada; empeora, hace reflorecer más la voz profética de la Iglesia. Lo que funciona es ponerse a cambiar desde la posición de cada uno, del gobierno, del capital, del obrero, del mozo de trabajo, del propietario de fincas: más justicia, más amor. ${ }^{45}$

Romero se refería con frecuencia a los hechos cotidianos de la realidad nacional. Siempre sus conceptos eran directos, sin vueltas. Por ello era buscado constantemente para escuchar sus opiniones. En una entrevista concedida a periodistas estadounidenses, el 22 de marzo de 1980, dos días antes de su asesinato, se le preguntó: "El Partido Demócrata Cristiano forma parte del gobierno junto con las Fuerzas Armadas. ¿Tiene un apoyo amplio por parte del pueblo?” A lo que contestó:

Han perdido una base muy amplia. Sus intenciones son buenas, trabajan con buena fe; pero en el terreno de los hechos está claro que el pueblo los tiene por parcialmente responsables de la represión. Quizá sean ellos los responsables de las reformas, que sí son buenas, pero han contribuido a la expansión de la represión. Esto es lo que desconcierta a la gente. Los democristianos quieren llevar a cabo sus reformas como si todo estuviera en orden, y así parece que la reacción de las organizaciones populares sea injusta. Pero los organismos populares no reaccionan contra las reformas, sino contra la represión. $Y$ en esto tienen razón. ${ }^{46}$

Una respuesta clara y directa, como se ve. Esto es común en las expresiones de Romero: su lectura de los hechos y sus comentarios no quieren encerrar análisis profundos, pero sí van directamente a la cuestión. Es una actitud honesta frente a los hechos.

En esta misma entrevista, se le pide un comentario ante el hecho que "La Junta que gobierna en la actualidad El Salvador acaba de publicar una Ley de Reforma Agraria. Los críticos denuncian que la ley va a ser utilizada para enmascarar la creciente opresión en el campo". Contesta Romero:

La reforma agraria es algo bueno, sin duda. Ha expropiado una propiedad de más de 1.200 yugadas y la ha dado al pueblo. En sí, esto es bueno.

45. Arzobispado de San Salvador, Mons. Oscar A. Romero. Su pensamiento, Tomo II, Ed. Librería del arzobispado, San Salvador, 2000, homilía del 14.07.77, en la misa exequias del P. Rutilio Grande.

46. Citado por Sobrino, Martín-Baró, Cardenal, en op.cit., pág. 448. 
Pero el peligro está en que, junto a esta Reforma, se ha declarado el estado de sitio, aparentemente para impedir que la derecha estorbe la reforma. Pero en realidad no ha hecho más que crecer dramáticamente la represión contra el pueblo. En lugares no afectados por la reforma agraria, están actuando los militares y son oprimidas las gentes. Por eso huyen y se vienen aquí, a San salvador, o se van a dormir al monte: pues si las fuerzas de seguridad los encuentran por las noches son hombres muertos. Unidades armadas chequean viviendas campesinas, incendian propiedades de agricultores y asesinan personas. En el campo el terror va en aumento en todas partes. La reforma agraria es algo bueno en sí; pero va acompañada de tortura y represión que destruyen la buena voluntad que había en la ley de reforma. Por eso no la apoya el pueblo. ${ }^{47}$

Queremos hacer referencia aquí, brevemente, a un hecho singular: el 15 de octubre de 1979 sucedió en el país un hecho que suscitó amplias expectativas: los 'militares jóvenes' del ejército salvadoreño tomaron el poder derrocando al presidente electo por voto fraudulento por el Partido de Conciliación Nacional (PCN), general Carlos Humberto Romero. Menjívar Ochoa describe este hecho con estas palabras:

El golpe de estado del 15 de octubre de 1979 fue el más anunciado de la historia salvadoreña. También fue el que mostró mejores intenciones y reunió a una mayor gama de personas y sectores con vocación de cambio, cada cual desde su perspectiva. Todas esas intenciones, toda esa vocación, no lograron crear un frente común ni encauzar el descontento para evitar la catástrofe que se anunciaba. ${ }^{48}$

La 'catástrofe anunciada' fue la guerra civil que asoló el país entre los años 1980 y 1992. El contexto, uno de los de mayor efervescencia social y política del país del siglo pasado: un sistema que se agotaba en sí mismo por no encontrar respuestas adecuadas a los reclamos sociales; un poder político que carecía de representatividad y de credibilidad, tanto por su forma de acceder al poder como por su incapacidad para dialogar con los sectores mayoritarios; una institucionalidad cuestionada que debía responder a las presiones de la vieja oligarquía nacional... En suma, un sistema político incapaz de escuchar las necesidades de las mayorías, y por ende, incapaz de crear los espacios institucionales para un reparto equitativo de la riqueza.

Romero fue un excelente 'lector' de la realidad que lo circundaba. Poco antes del golpe de estado, precisamente, en su Cuarta Carta Pastoral, del 6 de agosto

47. Ídem, 446.

48. Menjívar Ochoa, Rafael, Tiempos de locura. El Salvador 1979-1981, Facultad Latinoamericana de Ciencias Sociales (FLACSO), San Salvador, 2006, pág. 73. 
de 1979, citando el documento de la Conferencia Episcopal Latinoamericana (CELAM) de Puebla en ese año de 1979, pintaba este panorama de la situación del país. De estas líneas podría decirse que Romero conocía de la posibilidad de un golpe de estado: tal es el panorama del país que presenta. Es pertinente detenerse un momento en esto:

Con Puebla podemos también denunciar el grave deterioro de la situación política que institucionaliza la injusticia. Se ha deteriorado 'la participación ciudadana en la conducción de sus propios destinos' (n. 46). 'Se ve con malos ojos la organización de obreros, campesinos y sectores populares y se adoptan medidas represivas para impedirla. Este tipo de control y de limitación de la acción no acontece con las agrupaciones patronales que pueden ejercer todo su poder para asegurar sus intereses'.

La proclama que justificaba el golpe de estado presentaba cuatro 'cargos' que, a juicio de la Junta, justificaban el golpe:

"1. Ha violado los derechos humanos del conglomerado.

2. Ha fomentado y tolerado la corrupción en la Administración Pública y de la justicia.

3. Ha creado un verdadero desastre económico y social.

Ha desprestigiado profundamente al país y a la noble institución armada $^{49}$

La proclama presentaba una situación social que se acercaba a los conceptos de Monseñor Romero que citaba frecuentemente. El obispo los presentaba de esta manera:

b. Convencida (la Fuerza Armada de El Salvador) de que los problemas anteriormente mencionados son el producto de anticuadas estructuras económicas, sociales y políticas que han prevalecido tradicionalmente en el país, las que no ofrecen para la mayoría de los habitantes las condiciones mínimas necesarias para que puedan realizarse como seres humanos. Por otra parte, la corrupción y la falta de capacidad del régimen, ha provocado desconfianza en el sector privado por lo que cientos de millones de colones se han fugado del país, acentuándose así la crisis económica en perjuicio de los sectores populares

c. Conocedora con certeza de que los gobiernos en turno, productos a su vez de escandalosos fraudes electorales, han adoptado programas inadecuados de desarrollo, en los que los tímidos cambios de estructuras planteados han sido frenados por el poder económico y político de sectores conservadores. Los cuales en todo momento han defendido

49. Proclama de la Fuerza Armada de El Salvador. 15 de octubre de 1979, Apéndice 2, en Rafael Menjívar Ochoa, op.cit., pág. 218. 
sus privilegios ancestrales de clases dominantes, poniendo incluso en peligro al capital consciente y de proyección social del país, el cual ha manifestado su interés en lograr un desarrollo económico justo de la población. ${ }^{50}$

Los comentarios de Romero hacen alusión al contendido de la proclama de la Junta de Gobierno, a los que añade algunos otros contenidos, de su propia lectura de los hechos. Por ejemplo, el hecho de que la corrupción y la falta de capacidad del régimen, ha provocado desconfianza en el sector privado por lo que cientos de millones de colones se han fugado del país, formaba parte de la lectura particular que Romero hacía de los hechos.

Los objetivos de la Junta de Gobierno revolucionaria eran sumamente ambiciosos. Probablemente nunca se habían expresado de esta forma en la Historia del país, desde la institucionalidad, en forma tan arriesgada. La proclama menciona tres objetivos. Vale la pena mencionarlos: cese a la violencia y corrupción, garantizar la vigencia de los derechos humanos y adoptar medidas que conduzcan a una distribución equitativa de la riqueza nacional, incrementando al mismo tiempo, en forma acelerada, el producto territorial bruto. ${ }^{51}$

Veamos aquí algunas de las reacciones de Romero frente al golpe de estado, que provocaron ese diálogo al que aludíamos arriba. Para ello, conviene detenerse en sus comentarios públicos en los días inmediatamente posteriores al golpe. Haciendo alusión, precisamente, al golpe de estado, decía:

Se ha invocado el derecho de instrucción (sic) (insurrección). El artículo $7^{\circ}$ de nuestra Constitución dice: 'Que los pueblos tienen derecho de insurreccionarse cuando el bien común está en peligro bajo una tiranía'.

La Constitución de El Salvador dice, en su artículo 87, en el apartado dedicado al Estado, su forma de gobierno y su sistema político, que

Se reconoce el derecho del pueblo a la insurrección, para el sólo objeto de restablecer el orden constitucional alterado por la transgresión de las normas relativas a la forma de gobierno o al sistema político establecido, o por graves violaciones a los derechos consagrados en esta Constitución. ${ }^{52}$

Sin duda, es bien difícil definir qué debe entenderse por 'pueblo' en este caso. La Constitución no lo define. Continúa Romero:

50. Ídem

51. Ídem, pág 219.

52. Constitución de El Salvador, Art. 87, Legislación Básica del Escolar Salvadoreño, Ed. Lis, San Salvador, 2004. 
En mi carta pastoral yo he recordado este principio cuando dice: 'La Encíclica Populorum Progressio del papa Paulo VI, citadaen la Conferencia de Medellín, recoge la enseñanza clásica de la teología católica, según la cual 'es legítima una insurrección en el caso muy excepcional de una tiranía evidente y prolongada que atentara gravemente contra los derechos de la persona y damnificara peligrosamente el bien común del país, ya provenga de una persona ya de estructuras evidentemente injustas'.

Están presentados ya los dos documentos que, a juicio de Romero, justificarían el golpe de estado: éste encontraría justificación en la Constitución Nacional y en la Doctrina Social de la Iglesia. Y concluye de esta forma su mensaje:

Creo, pues, que los condicionamientos para una insurrección existían en El Salvador. La Iglesia no es la que va a decidir cuándo es la hora de la insurrección, Ella solamente propone el principio teológico. Y cuando los expertos en política y todos aquellos que pueden manipular una insurrección creen que llenan las condiciones que la Iglesia señala, y de veras las llenan, tenemos el caso de una insurrección legítima.

Esta es la posición de la lglesia: estamos en pleno derecho de insurrección y la insurrección fue legítima...53

Llama fuertemente la atención en esta breve cita las palabras los condicionamientos para una insurrección existían en El Salvador. Desde la más alta institucionalidad eclesial, públicamente, el arzobispo justificaba un golpe de estado. Jamás la jerarquía de la Iglesia católica se había atrevido a tanto. Nótese también que la justificación está fundamentada, primeramente, en la Constitución Nacional; luego, en la Doctrina Social de la Iglesia, en la encíclica del Papa Paulo VI Populorum Progressio, de 1967. Las palabras finales de esta breve cita son contundentes: la insurrección fue legítima.

Sería sumamente interesante seguir este 'diálogo' entre Monseñor Romero y el contexto político, pero escapa al objetivo de este escrito. Veamos otro acontecimiento. Romero no dejó ningún estamento sin aludir. Esta otra cita está dirigida al gobierno de Estados Unidos, presidido en ese entonces por James Earl Carter ${ }^{54}$. Este país había venido brindando una cada vez más grande asistencia militar al gobierno del país, situación que había recibido severas críticas. Había interrumpido la ayuda militar ante las serias acusaciones de violaciones a los derechos humanos que se hacían desde diversos ámbitos al

53. Citado en Monseñor Oscar A. Romero. Su pensamiento. VII, Misión de la Iglesia en medio de la crisis del país, $29^{\circ}$ Domingo del Tiempo Ordinario, 21 de octubre de 1979, Arzobispado de San Salvador, San Salvador, 2000, pág 354 ss.

54. James Earl “Jimmy” Carter, Jr. fue Presidente de Estados Unidos entre 1975 y 1980. Carter recibió el Premio Nóbel de la Paz en 2002, galardonado por sus esfuerzos para encontrar soluciones pacíficas a los conflictos internacionales, por impulsar la democracia y los derechos humanos, y por fomentar el desarrollo económico y político de los pueblos. 
gobierno. La Junta Revolucionaria de Gobierno había prometido en su proclama 'garantizar la vigencia de los derechos humanos'. Ante ello, el gobierno de Carter prometía reanudar la ayuda militar. Ante esto, Romero mandó una carta al presidente Carter, que luego hizo pública en una de sus homilías, solicitando que deje de lado prometida ayuda militar al gobierno:

Otra petición, más delicada: al gobierno de los Estados Unidos: 'Que según la noticia de La Prensa Gráfica del 17 de corriente, titula: Alentador califica golpe en el país Estados Unidos de América' (sic). Dice dentro en el texto: "'...Y que Estados Unidos considerará reanudar su asistencia militar si la nueva Junta mejora la situación de los Derechos Humanos'. La carta pregunta: ‘Qué ya se les olvidaría lo que en su reciente visita pidió el Papa para los países pobres? Estamos hartos de armas y balas... El hambre que tenemos es de justicia, de alimento, medicinas, educación y programas efectivos de desarrollo equitativo. Si se llega a respetar los derechos humanos lo que menos necesitamos serán armas ni métodos de muerte... ${ }^{55}$

No dejaba de tener razón la fuente citada por Romero: resulta paradójico que un gobierno que proclama hacer respetar la vigencia de los derechos humanos resultase por ello merecedor de ayuda en armas.

El testimonio de José Jorge Simán Jacir, dice a este respecto, al preguntársele acerca de la carta enviada al presidente Carter:

Sencillamente. Monseñor se daba perfecta cuenta de la incidencia del gobierno americano en la vida del país, en el proceso de lo que estaba ocurriendo. Y cuando Carter llega a la presidencia de los EE.UU., (sic) Monseñor ve, a través de sus palabras, su buena voluntad y sus sentimientos, y esto lo anima a escribirle una carta dándole su versión de los hechos, de la situación del país.

Esta carta él la escribió, pero lógicamente, escuchó opiniones, sugerencias. Tenía apoyos, como cualquier otra persona que está en una posición como esa. Tenía ayudantes, como los padres Moreno, Sobrino, Estrada, Amaya, Urioste, César Jerez, además de laicos (Roberto Cuéllar y otros), pero -como me dijo Sobrino-, el que decidía cuál debía ser el espíritu del documento, qué elementos debía contener, que había que plantear y cómo, el que redondeaba y daba la versión final era Monseñor.... ${ }^{56}$

El domingo 23 de marzo de 1980, un día antes de su asesinato, en la homilía de la misa, que era escuchada por miles de personas, Monseñor Romero hizo un

55. Ídem, pág. 368.

56. Simán, José Jorge, op.cit., pág. 29. 
llamado público contra la represión por parte del gobierno, incitando incluso a la desobediencia de quienes debían cumplir las órdenes, en lo que quizá sea su homilía más famosa: hizo un llamado a los soldados para que no obedecieran la orden de matar:

Yo quisiera hacer un llamamiento, de manera especial, a los hombres del ejército. Y en concreto, a las bases de la Guardia Nacional, de la policía, de los cuarteles... Hermanos, son de nuestro mismo pueblo. Matan a sus mismos hermanos campesinos. $Y$ ante una orden de matar que dé un hombre, debe prevalecer la ley de Dios que dice: "No matar". Ningún soldado está obligado a obedecer una orden contra la Ley de Dios. Una ley inmoral, nadie tiene que cumplirla. Ya es tiempo de que recuperen su conciencia, y que obedezcan antes a su conciencia que a la orden del pecado. La Iglesia, defensora de los derechos de Dios, de la Ley de Dios, de la dignidad humana, de la persona, no puede quedarse callada ante tanta abominación. En nombre de Dios, pues, y en nombre de este sufrido pueblo, cuyos lamentos suben hasta el cielo cada día más tumultuosos, les suplico, les ruego, les ordeno en nombre de Dios: ¡Cese la represión! ${ }^{57}$.

Este fragmento de su homilía fue interrumpido seis veces por aplausos. Era sabido que los agentes paramilitares asistían a sus misas y a todas las manifestaciones públicas de Romero. Hablaba, por lo tanto, a los agentes que estaban presentes, mezclados con los feligreses, y a los que lo escuchaban por radio: sus homilías se transmitían por radio y tenían una amplia repercusión en los medios de comunicación social, así como todos sus discursos. ${ }^{58}$

La repercusión que tuvo este mensaje, probablemente, apuró a quienes ya planeaban el asesinato de Romero a decidir la operación. El entonces mayor Roberto D'Aubuisson, el entonces capitán Álvaro Saravia y el empresario Fernando Sagrera, entre otros, estuvieron presentes en la reunión que decidió el asesinato ese 24 de marzo de 1980, en la residencia de Alejandro Cáceres, en San Salvador. Hasta allí llegó el Capitán Eduardo Ávila y avisó que el obispo Romero oficiaría una misa ese mismo día en la capilla del Hospital Divina Providencia. ${ }^{59}$ Entonces $D^{\prime}$ Aubuisson ordenó se llevara a cabo el asesinato planeado y encomendó la operación a Saravia. ${ }^{60}$

Ese 24 de marzo de 1980, a las 6:25 de la tarde, un francotirador disparó desde el vehículo, detenido frente a la entrada principal de la capilla del Hospital

57. Monseñor Oscar A. Romero. Su pensamiento. VIII, Arzobispado de San Salvador, San Salvador, 2000, pág 155. 58. Un buen comentario de esta homilía, en Miguel Cavada Diez, Romero. Cese la represión, Grupo Maíz, San Salvador, 2006.

59. Naciones Unidas, Comisión de la Verdad, Informe. De la locura a la esperanza. La guerra de 12 años en El Salvador, 1992-93, San Salvador, 1995, pág. 170-180.

60. Estos y otros detalles fueron referidos por Álvaro Saravia al periódico digital El Faro publicada el 22 de marzo de 2010 y titulada 'Así matamos a Monseñor Romero'. 
Divina Providencia, donde Romero oficiaba misa en ese momento; bastó una sola bala para ultimar a Romero. Al momento del disparo, había ya pasado la homilía de la misa, en la que Romero había animado a los presentes a mirar la historia desde la esperanza:

"Yo les suplico, queridos hermanos, que miremos estas cosas desde el momento histórico, con esta esperanza..." 61 .

\section{Bibliografía y fuentes}

Arzobispado de San Salvador, Mons. Oscar A. Romero. Su pensamiento, Tomos I a VII, Ed. Librería del arzobispado, San Salvador, 2000.

Brockman, James R., en La Palabra queda. Vida de Mons. Oscar Romero, UCA Editores, San Salvador, 1985.

Browning, David, El Salvador, la tierra y el hombre, Edición de la División de Publicaciones del Ministerio de Cultura y Comunicaciones, $3^{\circ}$ edición, San Salvador, 1987.

Cardenal, Rodolfo, Historia de una Esperanza, vida de Rutilio Grande, UCA, San Salvador, 2002.

Cavada Diez, Miguel, Romero. Cese la represión, Grupo Maíz, San Salvador, 2006.

Colindres, Eduardo, Fundamentos económicos de la burguesía salvadoreña, Universidad Centroamericana José Siméon Cañas (UCA), San Salvador, 1977.

Constitución de El Salvador, Legislación Básica del Escolar Salvadoreño, Ed. Lis, San Salvador, 2004.

Delgado, Jesús, ‘Oscar Romero. Biografía’, UCA Editores, San Salvador, 1990.

El Diario de Hoy del 24.02.77.

González, Luis Armando, Estado sociedad y economía en El Salvador (18801999), en Cardenal, Rodolfo y González, Luis Armando (compiladores), El Salvador: la transición y sus problemas, UCA Editores, San Salvador, 2007.

61. Citado por Sobrino, Martín-Baró, Cardenal, op.cit., pág. 295; es un fragmento de la última homilía de Romero, el lunes 24.03.80, momentos antes de su asesinato. 
http://servicioskoinonia.org

http://www.celam.org/principal/

http://www.cervantesvirtual.com/bib_autor/romero/

La Prensa Gráfica, 2 de julio de 1977.

López Vigil, María, Monseñor Romero, piezas para un retrato', UCA Editores, San Salvador, $5^{\mathrm{a}}$ ed. 2001.

Martínez, Ana Guadalupe, Las cárceles clandestinas, UCA Editores, San Salvador, 1992, $2^{\circ}$ edición.

Menjívar Ochoa, Rafael, Tiempos de Locura: El Salvador 1979-1981, FLACSO, Programa El Salvador, San Salvador, 2007. 